\title{
E7-Targeted Nanotherapeutics for Key HPV Afflicted Cervical Lesions by Employing CRISPR/ Cas9 and Poly (Beta-Amino Ester)
}

\author{
Jinfeng Xiong ${ }^{1, *}$ \\ Songwei Tan $\mathbb{D}^{2, *}$ \\ Long $\mathrm{Yu}^{3}$ \\ Hui Shen' \\ Shen $\mathrm{Qu}^{4}$ \\ Chong Zhang ${ }^{2}$ \\ Ci Ren' \\ Da Zhu' \\ Hui Wang'
}

'Department of Obstetrics and Gynecology, Tongji Hospital, Tongji Medical College, Huazhong University of Science and Technology, Wuhan, People's Republic of China; ${ }^{2}$ Tongji School of Pharmacy, Tongji Medical College, Huazhong University of Science and Technology, Wuhan, Hubei, People's Republic of China; ${ }^{3}$ Department of Pathogen Biology, School of Basic Medicine, Tongji Medical College, Huazhong University of Science and Technology, Wuhan, Hubei, People's Republic of China; ${ }^{4}$ School of Basic Medicine, Tongji Medical College, Huazhong University of Science and Technology, Wuhan, Hubei, People's Republic of China

*These authors contributed equally to this work

\begin{abstract}
Introduction: Persistent HR-HPV (high-risk human papillomavirus) infection is the main cause of cervical cancer. The HPV oncogene E7 plays a key role in HPV tumorigenesis. At present, HPV preventive vaccines are not effective for patients who already have a cervical disease, and implementation of the recommended regular cervical screening is difficult in countries and regions lacking medical resources. Therefore, patients need medications to treat existing HPV infections and thus block the progression of cervical disease.

Methods: In this study, we developed nanoparticles (NPs) composed of the non-viral vector PBAE546 and a CRISPR/Cas9 recombinant plasmid targeting HPV16 E7 as a vaginal treatment for HPV infection and related cervical malignancies.

Results: Our NPs showed low toxicity and high biological safety both in vitro (cell line viability) and in vivo (various important organs of mice). Our NPs significantly inhibited the growth of xenograft tumors derived from cervical cancer cell lines in nude mice and significantly reversed the cervical epithelial malignant phenotype of HPV16 transgenic mice. Conclusion: Our NPs have great potential to be developed as a drug for the treatment of HPV-related cervical cancer and precancerous lesions.
\end{abstract}

Keywords: HR-HPV infection, cervical cancer, nanoparticles, PBAE, gene therapy, HPV16 transgenic mice

\section{Introduction}

Cervical cancer remains the leading cause of gynecological tumor-related mortality worldwide and the second most common malignancy in women, with 570,000 women diagnosed with cervical cancer and 311,000 dying from the disease each year. ${ }^{1-3}$ Persistent HR-HPV infection is the main cause of cervical cancer, ${ }^{4}$ with HPV16 and HPV 18 causing more than $50 \%$ and $10 \%-15 \%$ of all cervical cancers, respectively. ${ }^{5,6}$ The oncoproteins E6 and E7 are key factors in HPV-related carcinogenesis, targeting $\mathrm{P} 53$ and retinoblastoma $(\mathrm{RB})$ proteins, respectively, to promote abnormal cell proliferation and cause cancer. ${ }^{7,8}$ Another possible cause of cervical cancer is HPV integration, ${ }^{9}$ which induces the retention and stable expression of E7 in the human genome. ${ }^{10}$ During the long process from HPV infection to CIN and ultimately to cervical cancer, HPV oncogenes, especially E7, are key targets for prevention and treatment. $^{11}$

Currently, commercially available prophylactic HPV vaccines cover the major HPV types but are ineffective in patients who are already infected. ${ }^{12}$ Current treatments for HPV infection-related cervical lesions include interferon therapy
Correspondence: Da Zhu; Hui Wang

Tel + 86-27-8366335I

Fax +86-27-8366268I

Email 153938801@qq.com;

huit7I@sohu.com 


\section{Graphical Abstract}

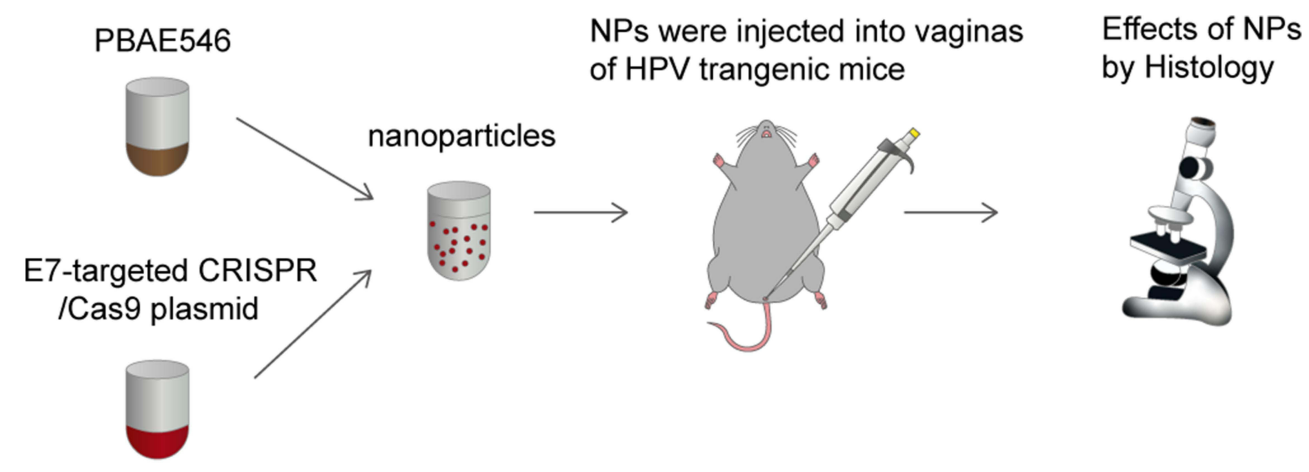

and physical therapy, but the efficacy is not satisfactory, and the loop electrosurgical excision procedure (LEEP) may increase the risk of miscarriage. ${ }^{13}$

In recent years, an increasing number of gene-targeted therapy techniques based on recombinant plasmids have been reported, such as targeted gene silencing by short hairpin RNA (shRNA) or RNAi and targeted gene knockout by CRISPR/Cas9. ${ }^{14-17}$ Studies have reported that compared to shRNA, the CRISPR technology performed with low noise, minimal off-target effects, and consistent activity across reagents. ${ }^{18}$ CRISPR/Cas9 system has the advantages of simple system components, convenient operation, high mutation efficiency, and low cost. ${ }^{19}$ It is undoubtedly a powerful tool for the prevention and treatment of HPV infection. ${ }^{20,21}$ However, because it is difficult for the plasmid to cross the cell barrier during vaginal administration and because local interference factors such as nuclease may degrade the plasmid, it is necessary to develop an appropriate vector to protect the recombinant plasmid from damage and deliver it reliably to the target cell. ${ }^{22,23}$ Delivery vectors are mainly divided into viral vectors and non-viral vectors. ${ }^{24}$ Viral vectors are restricted in clinical applications due to their safety issues. Non-viral vectors, which have been widely developed and adopted due to their low virulence and non-immunogenicity, ${ }^{25-27}$ include cationic liposomes, ${ }^{28}$ polyethyleneimine $(\mathrm{PEI})^{29}$ and poly ( $\beta$-amino ester) (PBAE). ${ }^{30,31}$

Among non-viral vectors, PBAEs are a widely used type of cationic polymer gene carrier with excellent biocompatibility, good biodegradability, easy production, and low cost. The positively charged PBAE can compress the plasmid into nanosized composite particles, protect the plasmid from nuclease degradation, and effectively deliver the plasmid to the cell to induce sequence-specific mRNA degradation or DNA double-strand breaks. In addition, PBAEs are $\mathrm{pH}$-sensitive, low in toxicity and highly-water soluble and they have high transfection efficiency in acidic drug delivery systems, which makes them compatible with the acidic vaginal environment. ${ }^{32-36}$ Therefore, in this paper, we have studied the efficacy of nanoparticles (NPs) composed of PBAEs and CRISPR/Cas9 recombinant plasmids targeting HPV16 E7 in HPV16-related cervical cancer, providing novel and promising ideas for the development of HPV-targeted drugs.

\section{Materials and Methods Materials, Cells and Animals}

1.5-Pentanediol diacrylate (B5) and 2-(3-aminopropylamino) ethanol (E6) were purchased from Aladdin (B136168, N184580, China). 4-Amino-1-butanol (S4) was purchased from ACROS Organics (C17635, Belgium). Branched poly(ethyleneimine) (water-free, $25 \mathrm{kDa}, \mathrm{bPEI}$ ) and cationic liposome HP were purchased from Sigma-Aldrich (408727, USA). The plasmids pDest-EGFP-N1 (plasmid 31796, GFP) and pAAV-CAG-RFP (plasmid 22910, RFP) were purchased from Addgene. The HPV16 E7-targeting CRISPR vector YKO-RP003-Ctrl and the HPV16 E7-targeting CRISPR plasmids were synthesized by UBIGENE (Wuhan, China). The sequences were chosen as the best of the three guide RNAs (gRNAs) designed from the Red Cotton Website (https:// www.rc-crispr.com/) and are described in Supplementary Table 1. Plasmid DNA was prepared using an endotoxin-free plasmid extraction kit (Omega, USA) and stored at $-80^{\circ} \mathrm{C}$.

The cervical cancer cell lines $\mathrm{SiHa}$ (HPV16 positive), HeLa (HPV16 negative, HPV18 positive), CaSki (HPV16 positive), and the HEK cell line HEK293 (HPV negative) 
were purchased from ATCC and passaged in our laboratory. The S12 cell line (HPV16 positive) is an immortalized human cervical keratinocyte cell line and was a generous gift from Professor Kenneth Raj (Health Protection Agency) with permission from the original owner Professor Margaret Stanley. ${ }^{37} \mathrm{SiHa}$, HeLa, and HEK293 cells were cultured in DMEM supplemented with 10\% fetal bovine serum (FBS). CaSki cells were grown in RPMI-1640 supplemented with 10\% FBS. S12 cells were maintained in a 1:1 mixture of DMEM/F12 (Gibco) and Ham's F12 (Gibco) medium supplemented with $10 \%$ FBS, $24.3 \mathrm{mg} / \mathrm{mL}$ adenine, $0.5 \mathrm{mg} / \mathrm{mL}$ hydrocortisone, $8.4 \mathrm{ng} / \mathrm{mL}$ cholera toxin, $5 \mathrm{mg} / \mathrm{mL}$ insulin, and $10 \mathrm{ng} / \mathrm{mL}$ epidermal growth factor (EGF). All cells were cultured in a humidified incubator with $5 \% \mathrm{CO}_{2}$ at $37^{\circ} \mathrm{C}$.

C57BL/6 female mice and specific-pathogen-free BALB/c-nu nude mice were purchased from BEIJING HFK BIOSCIENCE, and HPV16 transgenic mice were provided by the National Cancer Institute (NCI) Mouse Repository (Frederick, MD, USA). All mice were housed at the SPF animal laboratory in the Experimental Animal Center, Tongji Medical College, Huazhong University of Science and Technology (HUST, Wuhan, China) and managed by Chinese law. The research was approved by the Experimental Animal Ethics Committee of Tongji Medical College of Huazhong University of Science and Technology.

\section{Synthesis of Poly (Beta-Amino Ester)546}

According to a literature review, ${ }^{32,33,38}$ we know that different PBAEs can be synthesized by systematically tuning the polymer backbone, side chain, polymer terminal group, and degradable linkages. The PBAE was synthesized in a 2-step procedure and experimentally verified (Figure 1). Briefly, polymer PBAE546 was synthesized as follows: 1.5-pentanediol diacrylate (B5) was mixed with 4-amino-1-butanol (S4) and stirred on a magnetic stir plate at $90{ }^{\circ} \mathrm{C}$ for $24 \mathrm{~h}$ with $2 \mathrm{~mL}$ of DMSO at a 1.2:1 molar ratio. After stirring, 2-(3-aminopropylamino) ethanol (E6) was added to the mixture (10-fold), and the mixture was stirred for $30 \mathrm{~s}$, incubated at room temperature for $1 \mathrm{~h}$, and precipitated in anhydrous diethyl ether to remove the solvent and monomers. The polymer was further purified by washing three times with diethyl ether and keeping it under vacuum with desiccant for $48 \mathrm{~h}$ to remove the final traces of ether. The chemical structure of PBAE546 was investigated by ${ }^{1} \mathrm{H}-\mathrm{NMR}$ (Bruker AVANCE III $400 \mathrm{MHz}$ NMR spectrometer) in $\mathrm{CDCl} 3$ as solvent. Polymers were then divided into smaller volumes and stored at $-20{ }^{\circ} \mathrm{C}$ with desiccant until needed.

\section{Preparation and Characterization of Poly (Beta-AminoEster)546-Plasmid Polyplex Nanoparticles}

PBAE546 (2 $\mu \mathrm{g} / \mathrm{L})$ was diluted with $25 \mathrm{mM}$ sodium acetate $(\mathrm{pH} 5)$ into 200ng plasmid with mass ratios of 5:1, 10:1, 20: 1, 40:1, 60:1, 80:1, and 100:1, respectively. PBAE546 and plasmid were mixed gently in $20 \mu \mathrm{L} \mathrm{NaAc}$ for $30 \mathrm{~s}$ and incubated at room temperature for at least 15 min. The particle size and zeta potential of the NPs were measured by laser light scattering (DB-525 Zeta PALS; Brookhaven Instruments, Holtsville, NY, USA).

\section{Transmission Electron Microscopy Imaging}

NPs composed of PBAE546/GFP were deposited on porous carbon film carbon-coated copper mesh and characterized by scanning electron microscopy with a Hitachi model microscope (Hitachi HT7700, Japan).

\section{Biocompatibility of Nanoparticles}

Working solutions were prepared by diluting PBAE546 with $25 \mathrm{mM}$ sodium acetate $(\mathrm{pH}$ ) at mass ratios of 20:1, 40:1, 60:1, and 80:1 to a GFP plasmid. SiHa, HeLa, CaSki GFP plasmid. SiHa, HeLa, CaSki, and S12 cells were inoculated in 96-well plates, with the same number of cells from each cell line in each well. Each well was transfected with $100 \mathrm{ng}$ of GFP. bPEI/GFP (weight ratio 3:1) diluted to $1 \mathrm{mg} / \mathrm{mL}$ in PBS was used as a positive control. The culture medium was replaced after $4 \mathrm{~h}$ of treatment with our NPs at room temperature. Cell viability was defined as the metabolic activity retained in each well after transfection, and it was measured at different time points using a Cell Counting Kit-8 (CCK-8, Dojindo) according to the manufacturer's instructions.

A total of $100 \mu \mathrm{L}$ of NPs (PBAE546/GFP 60:1, $100 \mu \mathrm{g}$ of plasmid) were injected into the thigh muscles of $\mathrm{C} 57 \mathrm{BL} / 6$ mice once a day for 3 days, and bPEI/GFP (bPEI/GFP 3:1) was injected as a and seventh days after the initial injection, the thigh muscles seventh days after the initial injection, the thigh muscles and other organs were harvested. Then, PBAE546/GFP and bPEI/GFP $(20 \mu \mathrm{L}$ of NPs containing $10 \mu \mathrm{g}$ of GFP) were pipetted into the vaginas of mice once a day for 20 days; the cervix and other organs were then harvested and fixed with paraformaldehyde. Toxicity was evaluated by hematoxylin-eosin (H\&E) staining. 

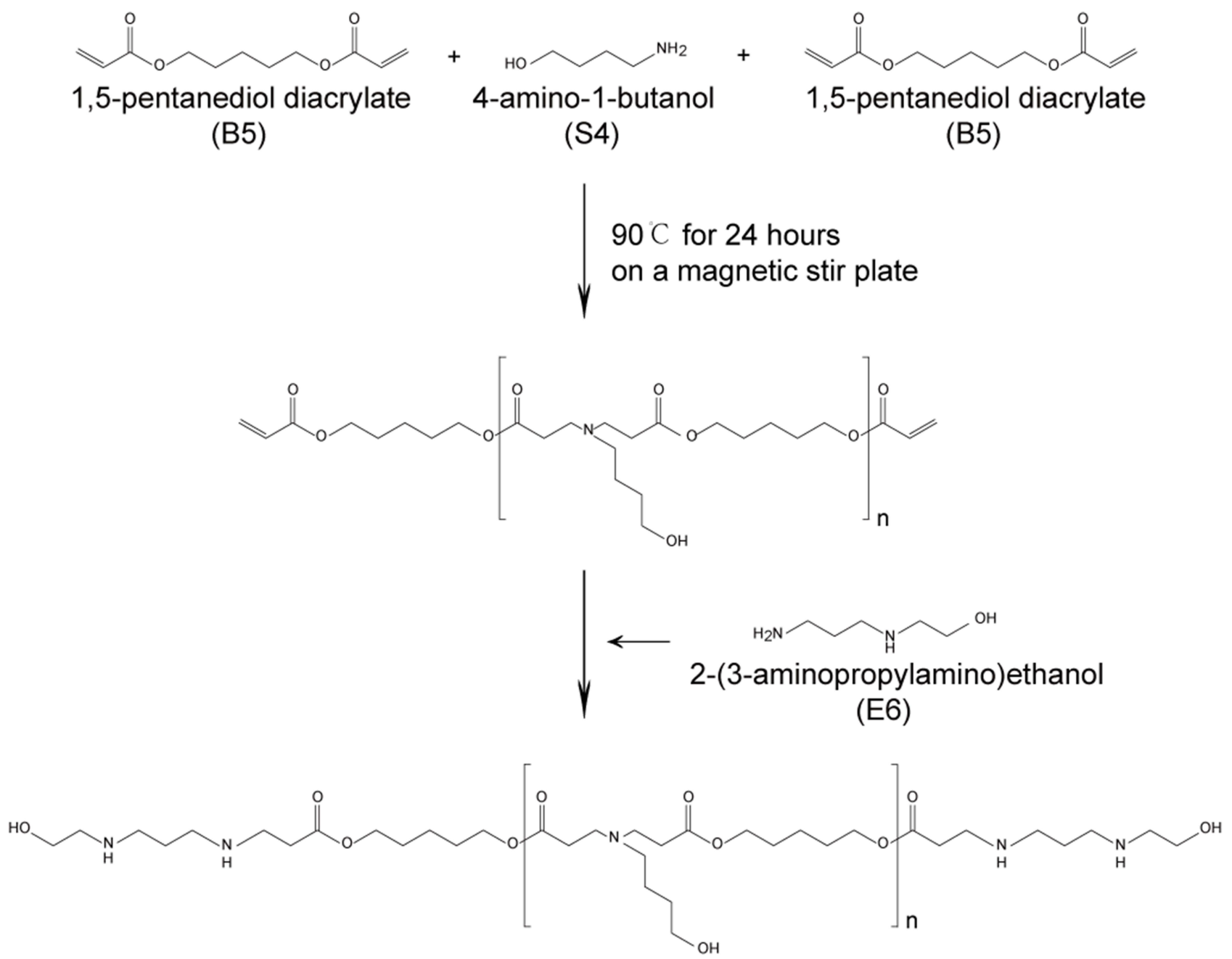

Poly ( $\beta$-amino ester)546 (PBAE546)

Figure I Synthesis of PBAE546. I.5-Pentanediol diacrylate (B5) was mixed with 4-amino-I-butanol (S4) and stirred on a magnetic stir plate at $90{ }^{\circ} \mathrm{C}$ for 24 h. 2-(3-aminopropylamino)ethanol (E6) was added to the mixture and stirred to form the PBAE546.

\section{Transfection Efficiency}

All cells were seeded in sterile 6-well plates at a density between $40 \%$ and $70 \%$ at transfection. Different mass ratios of NPs composed of PBAE546 and GFP (20:1, 40:1, 60:1, and 80:1) were mixed in $100 \mu \mathrm{L}$ of $25 \mathrm{mM}$ sodium acetate ( $\mathrm{pH} 5$ ). NPs were incubated at room temperature for 25-30 min before being added to plate wells containing $900 \mu \mathrm{L}$ of serum-free medium. The medium was replaced after $6 \mathrm{~h}$ of incubation. bPEI/GFP polyplexes (weight ratio 3:1, $2 \mu \mathrm{g}$ of GFP) were formed by mixing in PBS for $20 \mathrm{~min}$ and were then added to cells.

A final volume of $20 \mu \mathrm{L}$ of NPs were pipetted into the vagina of 4-week-old C57BL/6 mice once a day for three days. The vaginas were rinsed 3 times with PBS before each administration to remove vaginal mucus. Three days after administration, the mice were euthanized, and the cervix was separated and cryosectioned at $7 \mu \mathrm{m}$ using a frozen section machine (Thermo Fisher Scientific).

\section{Xenograft Experiments}

$\mathrm{SiHa}$ and HeLa cells $\left(5 \times 10^{6}\right)$ were injected subcutaneously into 4-week-old nude mice. When the tumor grew to nearly $35 \mathrm{~mm}^{3}$, the mice were randomly assigned to different groups. We administered intra-tumoral injections of $100 \mu \mathrm{L}$ of NPs coated with $60 \mu \mathrm{g}$ of plasmid (PBAE546/ plasmid 60:1) every 4 days. Subcutaneous tumors were collected after the mice were euthanized, and the tumor size was calculated using the following formula: $\mathrm{L} \times \mathrm{W}^{2} \times 0.5$. All experimental protocols were approved by the Institutional Animal Care and Use Committee of 
HUST, and the study was carried out in strict accordance with the Guidelines for the Welfare of Animals in Experimental Neoplasia.

\section{Transgenic Mouse Experiments}

Six-week-old HPV16-positive transgenic female mice were randomly divided into three groups for subsequent vaginal administration. After anesthesia with $4 \%$ chloral hydrate, the vagina was washed three times with $20 \mu \mathrm{L}$ of normal saline. NPs consisting of PBAE546 and $10 \mu \mathrm{g}$ of plasmids in a final volume of $20 \mu \mathrm{L}$ (PBAE546/plasmid $60: 1)$ were injected into the vaginas of the mice once a day for 20 days. Mice administered the drug were placed with their abdomens up for at least 30 min while under anesthesia to prevent the drug from flowing out of the vagina due to pressure. The mice were euthanized 20 days later, and the cervixes of the mice were dissected, separated and fixed in $4 \%$ paraformaldehyde. Then, the tissues were embedded in conventional paraffin, and pathological sections were obtained.

\section{Immunohistochemical}

Paraffin-embedded sections $(5 \mu \mathrm{m})$ were subjected to $\mathrm{H} \& \mathrm{E}$ staining and immunohistochemical (IHC) staining. The slides were incubated overnight at $4^{\circ} \mathrm{C}$ with rabbit antiHPV16 E7 (1:50, orb10573, Biorbyt), rabbit anti-P16 (1:100, A0262, Abclonal), rabbit anti-RB1 (1:100, 10048-2-Ig, Proteintech), rabbit anti-Ki67 (1:100, ab16667, Abcam), rabbit anti-CD34 (1:100, BA0532, Wuhan Boster Bio-Engineering), rabbit anti-CDK2 (1:400, ab6538, Abcam), and rabbit anti-E2F1 (1:200, 12171-1-Ap, Proteintech) as primary antibodies. Antibody detection was performed using diaminobenzidine (DAB). Images were photographed from three randomly chosen fields using cellSens Dimension (version 1.8.1, Olympus). To quantitatively analyze the expression level, the staining score was determined according to the staining depth and the ratio of positive stained positive cells. Dye depth: 0 is no dye, 1 is light yellow, 3 is brownyellow, 2 is between 1 and 3. The proportion of positive stained positive cells is calculated to the total number of cells. Staining score $=$ staining depth $\times$ positive stained cell ratio.

\section{Statistical Analysis}

All quantitative data are represented as the mean \pm SD from at least three parallel measurements. Statistical analysis was calculated using one-way ANOVA or Student's $t$-test by GraphPad Prism software with $P<0.05$ as the significant difference.

\section{Results}

\section{Synthesis and Characterization of Nanoparticles}

We used three monomers to synthesize a biodegradable poly ( $\beta$-amino ester) (PBAE) polymer for plasmid delivery: 1.5-pentanediol diacrylate (B5), 4-amino-1-butanol (S4), and 2-(3-aminopropylamino)ethanol (E6). The polymer was named PBAE546 according to the three monomers, which formed the backbone (B), side chain (S) and end cap (E) of the synthetic polymer. The synthesis scheme of PBAE546 is shown in Figure 1. The structure of PBAE546 was verified by ${ }^{1} \mathrm{H}-\mathrm{NMR}$ spectroscopy and all the peaks could be found as expected for the proposed chemical structures (Supplementary Figure 1A). NPs were prepared with different mass ratios of PBAE546 and GFP, and the plasmid encapsulation ability of PBAE546 was evaluated by agarose gel electrophoresis. When the mass ratio of PBAE546 to plasmid reached 40:1, most of the plasmids were coated by polymer and remained in the dot holes of the agarose gel without migration (Figure 2A). When the mass ratio was 60:1 or higher, almost no release of plasmids from NPs was observed. Dynamic light scattering showed that the particle size range of NPs with different mass ratios is $141.2 \mathrm{~nm}-$ $345.9 \mathrm{~nm}$, and the zeta potential range is $15.3 \mathrm{mV}-33.0 \mathrm{mV}$ (Figure 2B and C). The NP size was the smallest when the mass ratio was $40: 1$, suggesting that the interaction between PBAE546 and GFP plasmid was the closest at this mass ratio. Transmission electron microscopy (TEM) showed that the NPs of the PBAE546/GFP complex were spherical and homogeneous (Supplementary Figure $1 \mathrm{~B}$ and C) .

\section{In vitro and in vivo Uptake of Nanoparticles}

Efficient cell uptake and expression are the key to plasmid delivery for gene therapy. To investigate the expression efficiency of our NPs, PBAE546 was used as a vector to transfect the GFP plasmid into cell lines. Fluorescence microscopy and flow cytometry were used to evaluate the efficiency of the NPs transfection of five HPV-positive cell lines, SiHa, HeLa, S12, CaSki, MS751, and the HPV-negative cell line HEK293. (Figure 3A and B). The transfection efficiency of NPs in different cell lines varies in the same mass ratio. In general, when the mass ratio was 


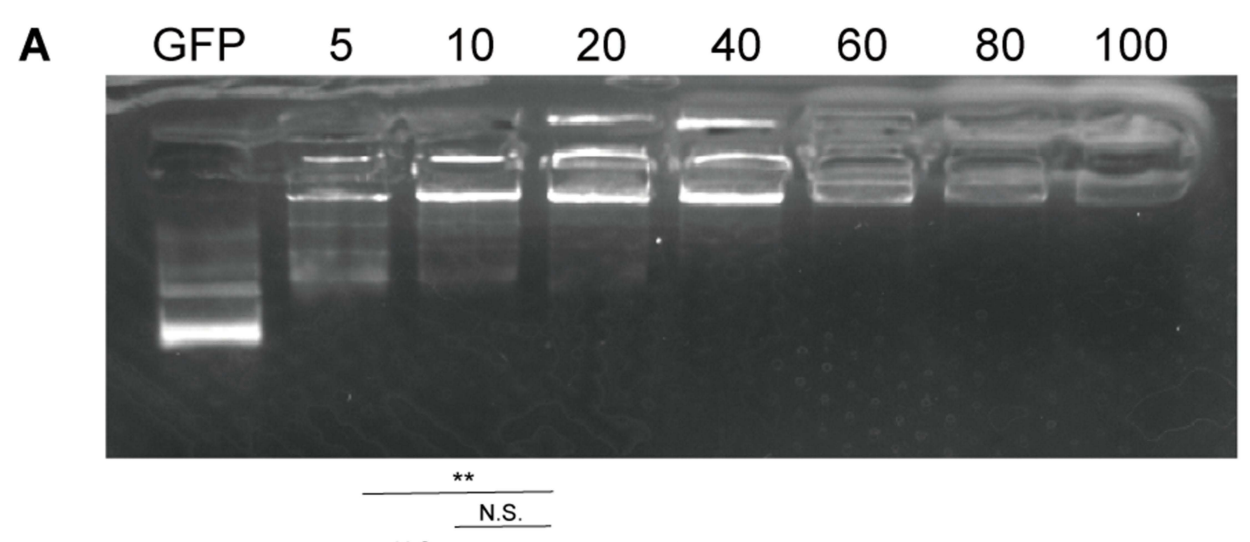

B

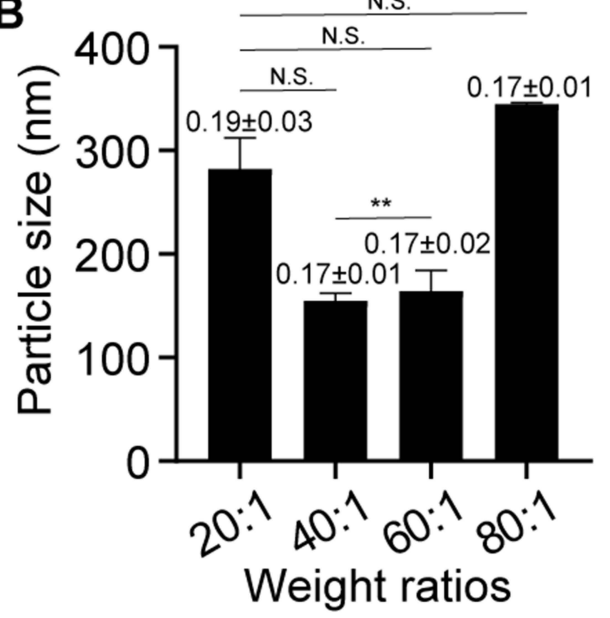

C

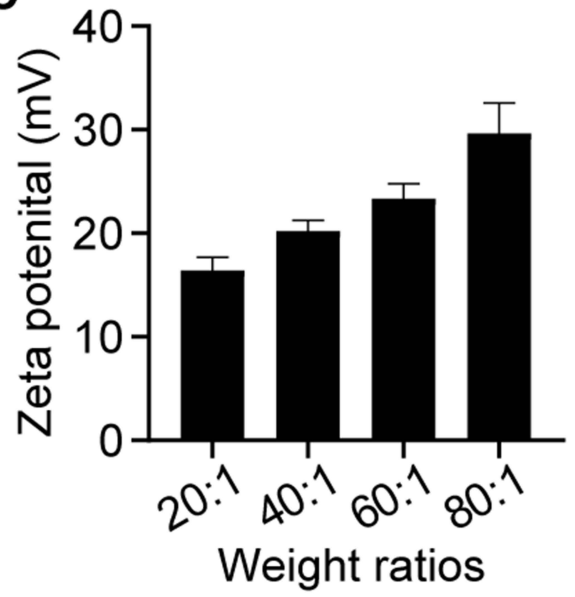

Figure 2 Characterization of NPs. (A) Agarose electrophoretic gel of NPs composed of GFP and PBAE546 with different mass ratios. (B) Particle sizes and PDI and (C) zeta potentials of NPs with different mass ratios (PBAE546:GFP) measured by dynamic light scattering. The data represent the mean \pm SD ( $n=3$ per group). One-way ANOVA was used for statistical analysis, $* P<0.05$, $* * P<0.01$, $* * * P<0.001$, $* * * * P<0.0001$.

Abbreviations: N.S, no significant difference.

60:1, the transfection efficiency was the highest $(86 \%$ in $\mathrm{SiHa}$ cells, 35.4\% in HeLa cells, 35.9\% in CaSki cells, $64.6 \%$ in $\mathrm{S} 12$ cells, $68.4 \%$ in MS751 cells, 99.9\% in HEK293 cells), even higher than that of the commercialize transfection reagent HP. TEM imaging of HEK293 cells transfected with PBAE546/GFP showed NPs in the vesicles of the cytoplasm, indicating that our NPs were taken up into the cells by endocytosis (Supplementary Figure 2).

Next, PBAE546/red fluorescent protein (RFP) NPs were administered vaginally to $\mathrm{C} 57 \mathrm{BL} / 6$ female mice to assess their uptake in vivo (Figure 3C). Considering that higher transfection efficiency is an important prerequisite for the best therapeutic effect, multiple sets of parameters were tested under the in vivo transfection conditions, including the mass ratio of PBAE546 to GFP, the dose of transfected plasmid, and the detection time point after treatment (Supplementary Figure 3). The results showed that the transfection efficiency was highest when the mass ratio was $60: 1$ and the plasmid dose was $10 \mu \mathrm{g}$ every 3 days, and detection occurred on the sixth day after treatment.

\section{Nanoparticles Showed Safety and Low Toxicity to Cervical Cancer Cells and Mice}

While pursuing the best therapeutic effect, the toxicity of NPs is an important factor that cannot be ignored. To investigate the cytotoxicity of our NPs, SiHa, HeLa, S12, and CaSki cells were treated with NPs at different mass ratios of PBAE546 to GFP for $6 \mathrm{~h}$ and then routinely cultured for $72 \mathrm{~h}$. Cell viability was detected by CCK-8 assay at $24 \mathrm{~h}, 48 \mathrm{~h}$, and $72 \mathrm{~h}$ (Figure 4A-D). Compared with the control group, NPs with mass ratios of 20:1, 40:1, and 60:1 did not significantly affect cell viability. When the mass ratio of NPs was as high as 80:1, different cell growth inhibition was observed in the four cell lines. 

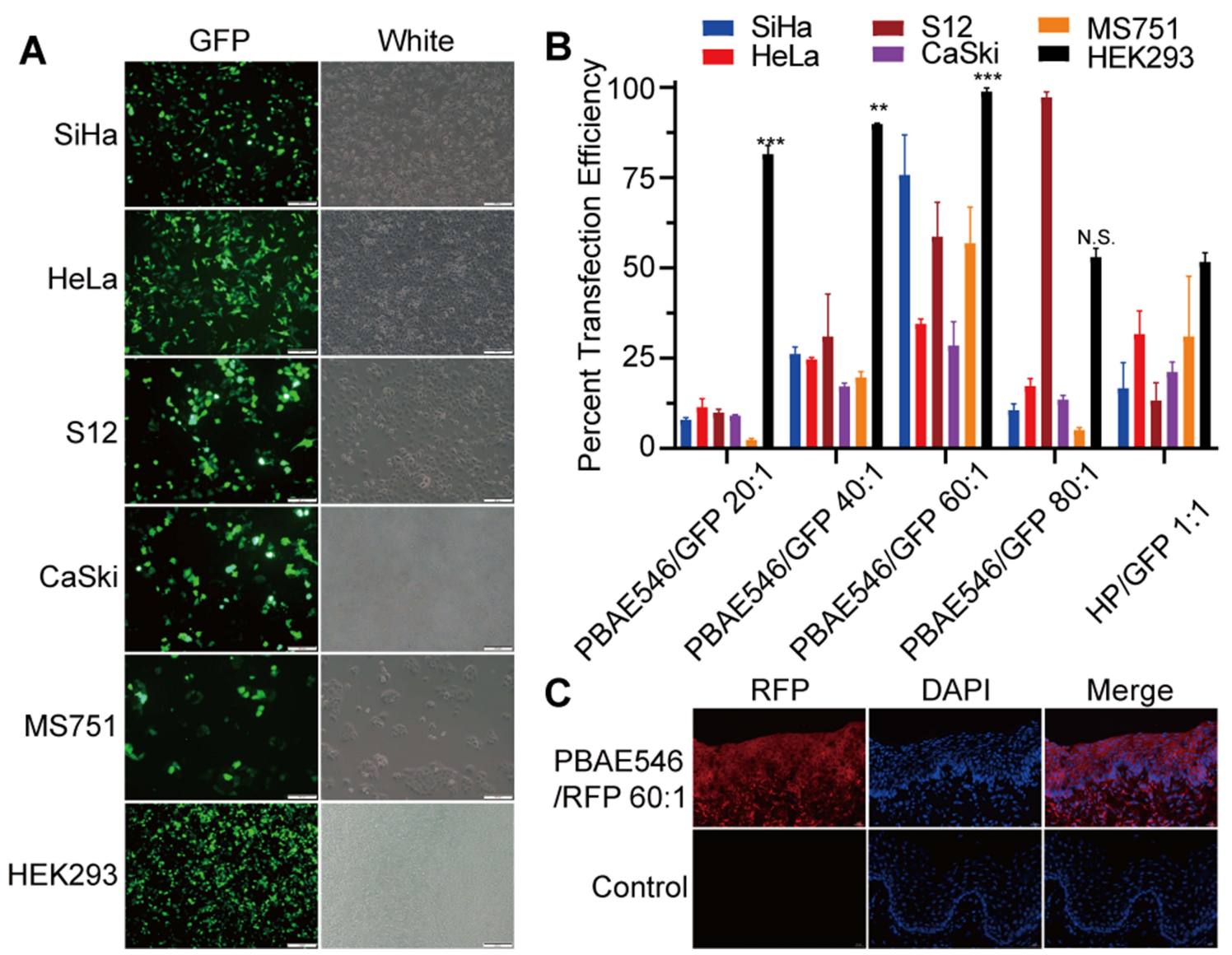

Figure 3 Uptake of NPs by cell lines and mouse uterine cervixes. (A) Representative images of SiHa, HeLa, SI2, CaSki, MS75I, and HEK293 cells 72 h after treatment with NPs (PBAE546/GFP 60:I). (B) Statistical uptake efficiency of PBAE546/GFP NPs with different weight ratios (20:I, 40:I, 60:I, and 80:I) compared with that of HP/GFP (I:I) by flow cytometry. (C) Representative images of fluorescence in the uterine cervixes of C57BL/6 mice treated with NPs (PBAE546/RFP, weight ratio 60:I, I0 $\mu$ g RFP once per day for three days) compared with control cervixes treated with NP-free $25 \mathrm{mM}$ sodium acetate. Scale bar, $20 \mu \mathrm{m}$. One-way ANOVA was used for statistical analysis, $*$ : $P<0.05$, ** $P<0.01$, *** $P<0.001$, ***** $P<0.0001$.

Abbreviations: N.S, no significant difference.

However, the growth inhibition induced by this high mass ratio was less than the cytotoxicity produced by bPEI/GFP 3:1. This indicates that our NPs have no obvious cytotoxicity when mass ratios are no more than 60:1.

Based on a review of the literature ${ }^{39}$ and the design of this study, we conducted maximum dose toxicity tests using $200 \mu \mathrm{g}$ and $300 \mu \mathrm{g}$ plasmids for vaginal and intratumoral administration, respectively. To further test the toxicity of NPs in andand toxicity was detected at the 11 th and the 21 st days after initiation of vaginal administration. Compared with the control group, the bPEI/ GFP (nonfluorescent and nontoxic empty plasmid) treatment group exhibited significant increases in the number of sites of inflammatory necrosis in the vaginal region and pyknosis of the liver nucleus, while no similar changes were observed in the 60:1 group treated with PBAE546/GFP (Figure 4E). No obvious toxicity was observed in the heart, spleen, lungs or kidneys (Supplementary Figure 4). NPs consisting of PBAE546 or bPEI coated with $100 \mu \mathrm{g}$ of GFP were injected daily into the thigh muscles of mice for 3 days, and toxicity tests were performed on day 4 and day 7 . In the bPEI/ GFP treatment group, local injection caused large-scale necrotic inflammatory infiltration of muscles (Figure 4F), and no obvious toxic reactions were observed in other important organs (Supplementary Figure 5). The results of hepatotoxicity in the vaginally administered bPEI group suggest that when developing vaginal drugs, special attention should be given to the possibility that the drugs may be absorbed into the circulation through the vagina and cause liver damage. The above data indicate the safety and low toxicity of our NPs, which are necessary characteristics for pharmaceutical use. 
A

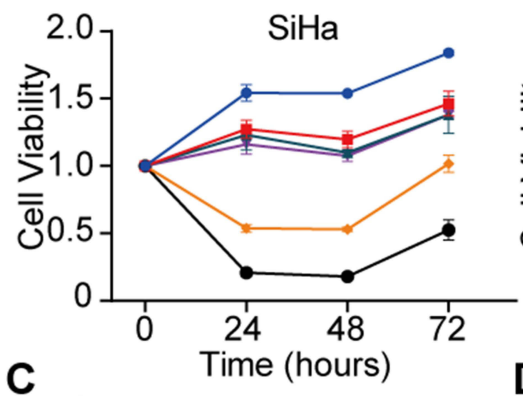

C

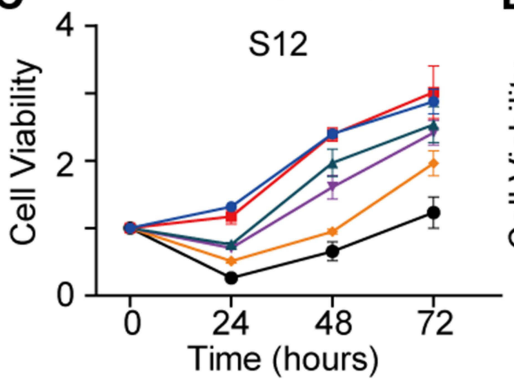

B

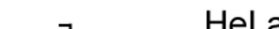

$\mathrm{HeLa}$
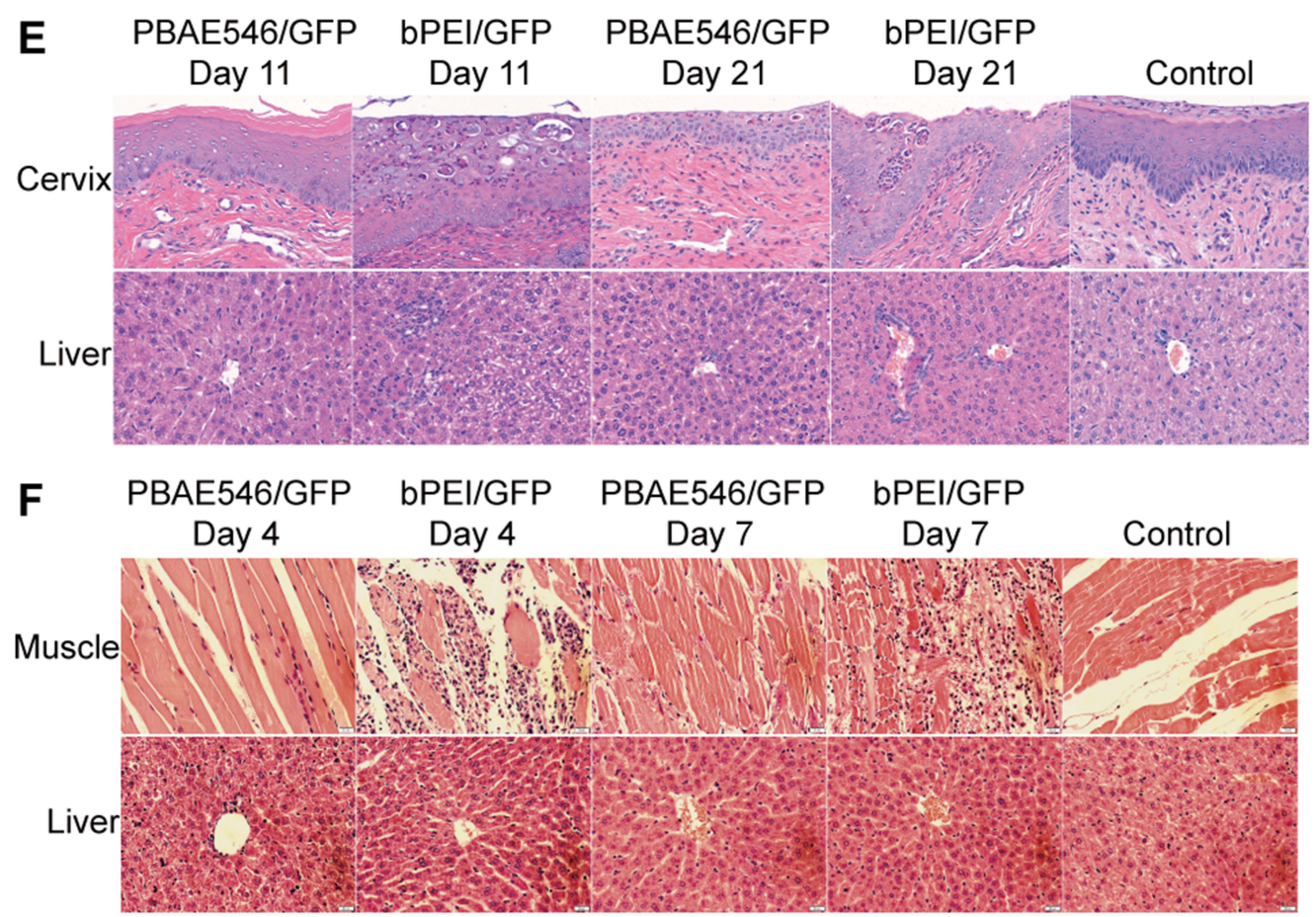

Figure 4 Analysis of NPs toxicity in cell lines and mouse organs. (A-D) The cytotoxicity of NPs composed of PBAE546/GFP with different mass ratios (20:I, 40:I, 60:I, and 80:I) was detected in (A) SiHa, (B) HeLa, (C) SI2, and (D) CaSki cell lines. bPEI/GFP(3:I) was used as the positive control. Toxicity is given as the viability of the cells remaining after treatment for $0 \mathrm{~h}, 24 \mathrm{~h}, 48 \mathrm{~h}$, and $72 \mathrm{~h}$. Each point represents the mean $\pm \mathrm{SD}(\mathrm{n}=3)$. (E) Representative images of H\&E-stained paraffin sections of cervix and liver tissues harvested from mice treated with NPs consisting of PBAE546/GFP (60:I) and bPEI/GFP (3:I) for 10 days and 20 days. The volume of NPs in the vagina of the treated mice was I0 $\mu \mathrm{L}$, containing $10 \mu \mathrm{g}$ of plasmid. Vaginal treatment was performed once a day for 20 consecutive days. (F) NPs generated by PBAE546/GFP (60:I) and bPEI/GFP I (3:I) were injected into the thigh muscle of mice for three consecutive days. Representative images of H\&E-stained paraffin sections of thigh muscle tissue and liver tissue of mice harvested on the fourth and seventh days after the first injection. A total volume of $100 \mu \mathrm{L}$ of NPs containing $100 \mu \mathrm{g}$ of plasmid was injected into the thigh muscles of mice each day. Scale bars, $20 \mu \mathrm{m}$. 


\section{Inhibitory Effects of Nanoparticles} Composed of Poly (Beta-Amino Ester) 546 and Therapeutic Plasmids on the Growth of

\section{Cervical Cancer Cells in vitro and in vivo}

We designed three sgRNAs (Supplementary Table 1) targeting HPV16 E7 and constructed the CRISPR/Cas9 plasmid.
HPV16-positive cells (SiHa, CaSki, and S12) and HPV16negative cells (HeLa) were processed with NPs (PBAE546/ plasmid 60:1) for $6 \mathrm{~h}$, and cell viability was detected by CCK-8 at $24 \mathrm{~h}, 48 \mathrm{~h}$, and $72 \mathrm{~h}$. Compared with the empty control plasmids, all three NPs effectively reduced the viability of HPV16-positive cells (Figure 5A-C), while no difference was observed in the viability of HPV16-negative HeLa cells
A

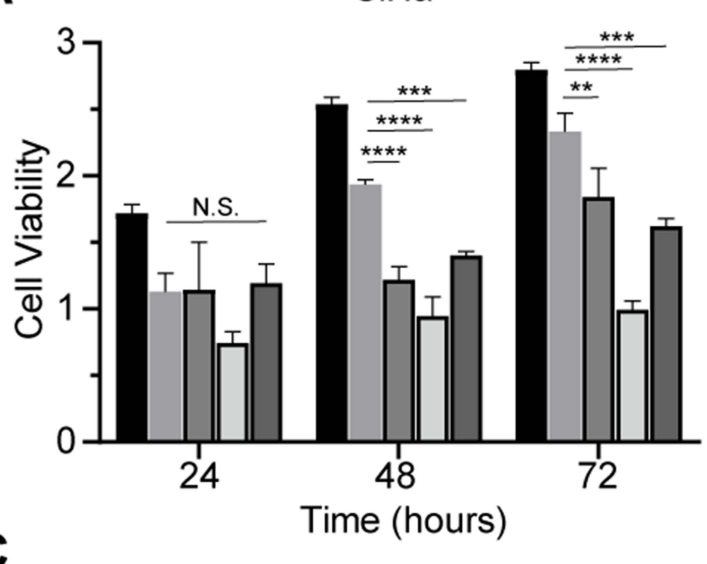

C

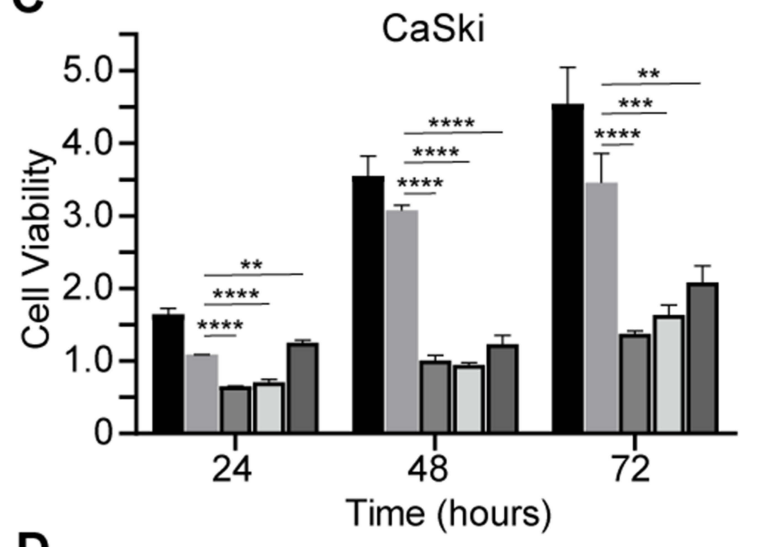

D

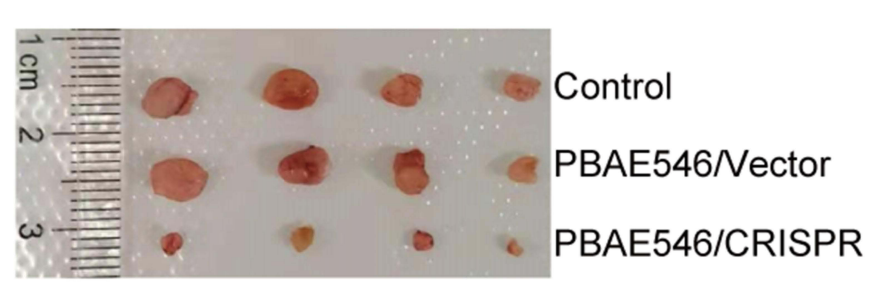

B

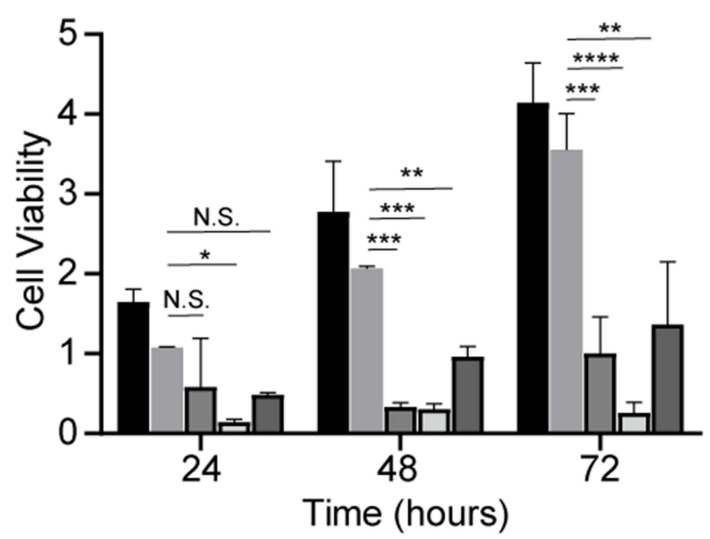

- Control

PBAE546/CRISPR Vector

PBAE546/CRISPR gRNA1

PBAE546/CRISPR gRNA2

PBAE546/CRISPR gRNA3

E

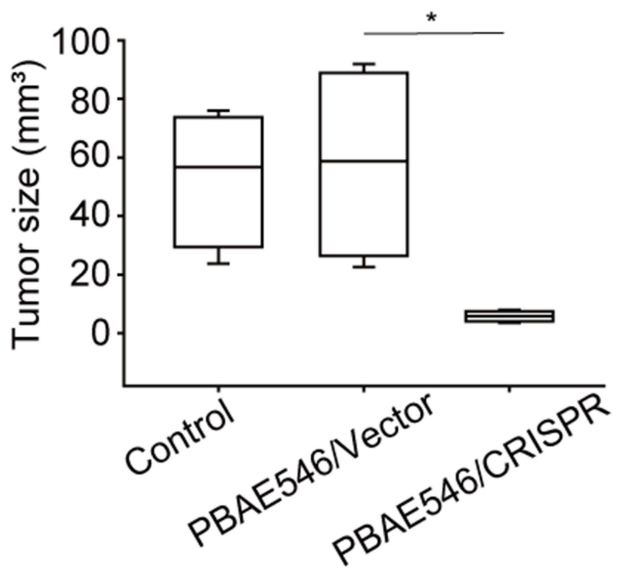

Figure 5 Growth inhibition of cervical cancer cells by PBAE546-therapeutic plasmid polyplex NPs in vitro and in vivo. (A-C) The CCK-8 method was used to detect the viability of (A) SiHa, (B) SI2, and (C) CaSki cells at 24 h, 48 h, and $72 \mathrm{~h}$ after treatment with NPs (PBAE546/plasmid 60:I) composed of PBAE546 and CRISPR/Cas 9 plasmid targeting HPVI6 E7. One-way ANOVA was used for statistical analysis, $*$ : $P<0.05$, $* *: P<0.01$, $* * *: P<0.001, * * * *$ : $P<0.0001$. (D-E) SiHa cells were injected subcutaneously into the right hind limb of BALB/c-nu mice. When the transplanted tumor grew to approximately $35 \mathrm{~mm}^{3}$, NPs consisting of PBAE546 and the CRISPR/Cas 9 plasmid targeting HPVI6 E7 were injected intratumorally (60:1). NPs were injected as a volume of $100 \mu \mathrm{L}$ containing $60 \mu \mathrm{g}$ of plasmid once every four days. (D) The subcutaneously formed tumors were photographed, and (E) the estimated sizes were measured after treatment with NPs.

Abbreviations: N.S, no significant difference. 
(Supplementary Figure 6A). To further explore the inhibitory effect of NPs on tumor growth in vivo, $\mathrm{SiHa}$ cells were inoculated subcutaneously in nude mice, and NPs were used for intra-tumoral injection therapy when the xenograft tumor grew to approximately $35 \mathrm{~mm}^{3}$. According to the results of in vitro experiments on cell lines, sgRNA2 had the best inhibitory effect on cell viability and was selected. It was administered every four days for 20 days. In SiHa subcutaneous tumor mice, the HPV16 E7 CRISPR-targeted group showed significant tumor growth inhibition and a significant reduction in tumor volume compared with the empty plasmid delivery group (Figure 5D and E). No differences between groups were observed in mice with HeLa subcutaneous tumors (Supplementary Figure 6B and C).

\section{Effect of Nanoparticles Targeting HPVI6 E7 on Protein Expression in Cervixes of HPVI6 Transgenic Mice}

For a closer approach to the primary clinical location of cervical cancer and to pursue noninvasive treatment, we used HPV16 transgenic mice to perform cervical in situ treatment through vaginal administration. After 20 days of continuous treatment, the malignant phenotype of the mouse cervical epithelium was significantly reversed in the NPs group targeting HPV16 E7. The proliferation of epithelial cells was inhibited, the basal cells were arranged neatly, and the volume of the nucleus was reduced. The cervical epithelium of the mice in the control group proliferated significantly (Figure 6A). The expression levels of HPV16 E7 and its related proteins were detected by immunohistochemistry. First, the expression of the target molecule HPV16 E7 and the surrogate marker of HRHPV infection P16 was significantly reduced, while the expression of the tumor suppressor gene $R B 1$, which interacts with the E7 oncoprotein, was restored. Second, the expression of the proliferation-related protein Ki67 and $C D 34$, the cell cycle-related protein $C D K 2$, and the transcription factor $E 2 F 1$ was significantly inhibited (Figure 6B). These results suggest that our NPs targeting HPV16 E7 can effectively reduce the expression of oncoproteins of target genes and affect related signaling

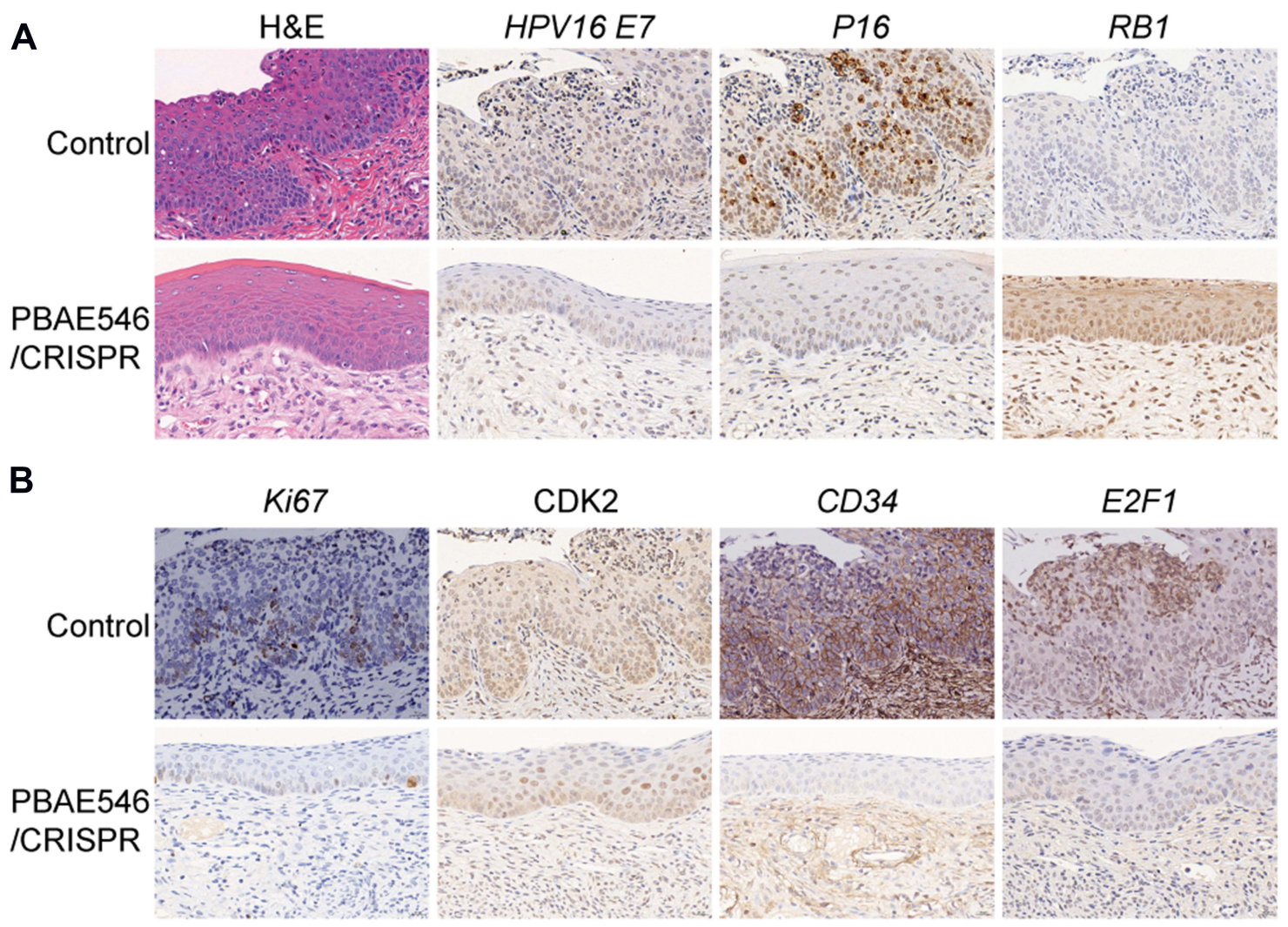

Figure 6 Therapeutic effect of NPs composed of PBAE546 and CRISPR/Cas9 recombinant plasmids targeting HPVI6 E7 in the vaginas of HPVI6 transgenic mice. (A and B) Representative images of H\&E and IHC staining of the cervical epithelium between the HPVI6 transgenic mouse control group and the HPVI6 E7 NPs (PBAE546/plasmid 60:I, $10 \mu \mathrm{g}$ of plasmid per day for 20 days) treatment group. IHC staining indicators included HPVI6 E7, PI6, RBI, Ki67, CDK2, CD34 and E2FI. Scale bars, 20 $\mu$ m. 
pathways, thus reversing the malignant phenotype of the cervical epithelia of HPV16 transgenic mice.

\section{Discussion}

There is no effective treatment for persistent HPV infection in clinical practice. ${ }^{40}$ The prevention of HPV-related cervical cancer or precancerous lesions relies on expensive HPV vaccines and repeated cervical screening. ${ }^{41}$ Even the ninevalent vaccine with the widest coverage currently does not fully cover all HPV subgroups that may cause infection. For most patients already infected with HPV, vaccination is not recommended. In addition, long-term repeated cervical screening has caused severe psychological pressure and financial burden to patients. Poor compliance may occur, or patients may even be lost to follow-up. It is difficult to achieve widespread implementation in countries and regions that lack medical resources. ${ }^{42,43}$ Moreover, patients with persistent HPV infection or CIN, especially most elderly patients, are more inclined to undergo diagnostic cone biopsy even if there is a risk of overtreatment. ${ }^{44,45}$ Therefore, it is necessary to develop drugs to treat HPV as a supplement to the vaccine.

The HPV E7 protein binds to Rb family members and targets them for degradation. This results in the release and activation of $\mathrm{E} 2 \mathrm{~F}$ transcription factors that drive the expression of $\mathrm{S}$ phase genes. The efficient binding of $\mathrm{Rb}$ by E7 can activate previously inhibited cell growth and apoptosis through a p53-dependent pathway. ${ }^{7}$ Our NPs block this process and induce apoptosis. It has been reported that targeting E7 with siRNA can effectively knock down the E7 mRNA level of HPV16 in HPVpositive cells, thus restoring the expression of inhibited RB1 and inducing cell apoptosis. ${ }^{46}$ However, the effect of siRNA is transient and easily degraded in the cell and cannot be inherited. ${ }^{47}$

The CRISPR/Cas9 system that can target the HPV16 E7 oncogene at the DNA level was selected in this study. The conditions for CRISPR/Cas9 system to successfully perform targeted cleavage are that the PAM sequence is correctly matched and sgRNA successfully binds to the target site, and Cas9 will perform DNA double-and cleavage at 3-4 nucleotides upstream of the PAM sequence. Therefore, CRISPR/Cas9 cutting efficiency is not affected by the number of copies of the target sequence. Episomal HPV is a complete sequence of about $7.9 \mathrm{~kb}$ containing E7 and can be targeted by our CRISPR/Cas9. According to previous studies on HPV integration, ${ }^{10}$ integrated HPV sequences may or may not contain E7. If the integrated
HPV sequence contains E7, then the CRISPR delivered by our NPs can also work. Integrated viruses reside in the nucleus of the human genome, while episomal viruses reside in the cytoplasm and nucleus of the cell. Therefore, any form of virus containing the E7 sequence can be destroyed by our NPs.

In recent years, some applications of non-viral gene delivery systems, including biological materials such as lipids, polymers, peptides and other materials that can bind or encapsulate nucleic acids, have become quite mature. For example, PBAE polymers with different chemical structures have been applied in the treatment of glioblastoma, small-cell lung cancer, breast cancer, pulmonary fibrosis and melanoma and have shown good efficacy. ${ }^{32,34,48-50}$ Liposome-templated hydrogel NPs (LHNPs) are considered a multifunctional CRISPR/Cas9 delivery tool for experimental research in cancer biology and the clinical transformation of cancer gene therapy. ${ }^{51}$ Folate receptor-targeted liposomes (F-LPs) were used to deliver the CRISPR/Cas9 system targeting the DNA methyltransferase DNMT1 gene in ovarian cancer. ${ }^{52}$ EGFP-targeted siRNA delivered by the vaginal perfusion of biodegradable poly(lactic-co-glycolic acid) (PLGA) NPs successfully silenced EGFP expression in transgenic GFP mice. ${ }^{53}$ Various nanomaterials have been proven to deliver nucleic acids (plasmids or siRNAs) for gene therapy, including vaginal applications.

The limitation of PBAEs lies in their stability in the blood, and large doses of PBAEs can cause hemolysis. Therefore, some researchers have attempted to modify PBAEs with mannitol and polyethylene glycol to improve their stability and reduce toxicity. ${ }^{34,54}$ In this study, we used the degradable non-viral nanomaterial PBAE546 for plasmid delivery because it is characterized by low toxicity, good biodegradability and high transfection efficiency. ${ }^{32-34,55}$ We believe that PBAEs are especially suitable for vaginal administration because the acidic vaginal environment is conducive to the stability of PBAE NPs, and vaginal administration greatly reduces the amount of PBAEs in the blood and significantly reduces the possibility of side effects such as hemolysis. Moreover, PBAE materials are transformable, and their optimization is worth further study to achieve higher curative effects and reduce side effects.

Our NPs showed high transfection efficiency and low biotoxicity (Figures 3-4). We found that HPV16 positive cell proliferation was significantly inhibited by the NPs in vitro experiments. The therapeutic effects of NPs have 
been observed for a longer time in vivo experiments. We injected NPs into the xenografts every 4 days for 20 days and observed slower growth of xenografts (Figure 5). We also pipetted NPs into the vaginas of HPV16 transgenic mice every day for 20 days. the hyperplasia of cervical vaginal epithelium was significantly inhibited, the expression of E7 and proliferation-related proteins was decreased, and the expression of apoptosis-related proteins was increased (Figure 6). Our NPs were used in HPV16 transgenic mice for 20 days, mimicking vaginal administration in the clinical trial. Previous studies have reported that vaginal administration of streptococcus vaginalis takes almost 3-7 days to achieve effective results. ${ }^{56}$ In addition, the E7 knockout effect is caused by CRISPR/Cas9 induced double-and DNA breakage and missense repair of target genes ${ }^{57}$ the therapeutic effects of our NPs are sustainable.

We used muscular and vaginal administration routes. The purpose of muscle administration is to avoid drug outflow, and the effect on other organs can be observed after being absorbed into the circulation system. The advantage of vaginal administration is to simulate the situation of a clinical trial, although a small part of the drug may flow out of the vagina. Our NPs are very close to the form of drugs, and their therapeutic effects on cervical cancer show promise for clinical transformation.

In this study, we delivered only a representative CRISPR/ Cas9 system targeting the HPV16 E7 oncogene. Other oncogenes of HPV16 and other HR-HPV may also contribute to cervical cancer. For example, the HPV E6 oncoprotein can cause cancer by degrading $\mathrm{p} 53,{ }^{58}$ and certain fragments of HPV can be integrated into the human genome, leading to increased genomic instability and causing cancer. ${ }^{59}$ The integration of HPV16 has been proposed as a potential marker of cervical tumor progression. ${ }^{60}$ For patients who have lost the opportunity for surgery or who have not yet reached surgical indications but require active treatment requirements, we can use virus capture sequencing to detect the HPV types or the specific information integrated with infected patients. This allows individualized treatment for different patients by delivering NPs that target specific HPV genes.

\section{Conclusion}

In conclusion, we developed NPs consisting of PBAE546 and CRISPR/Cas9 for the treatment of HPV infection. The advantages of our NPs are that they are stable and have good transfection efficiency in the acidic vagina, so they are very suitable to be prepared as a vaginal medicine. The
CRISPR/Cas9 released by our NPs disables HPV effectively by targeted knockout of E7. Therefore, our NPs can be used to treat cervicitis and CIN in the future, in the form of vaginal lotions and gels. Our work provides new hope for the clinical transformation of nanomedicine to treat cervical lesions, thereby preventing cervical cancer.

\section{Acknowledgments}

This work was supported by funds from National Natural Science Foundation of China (81830074, 81974412, 81772786,81502253 and 82002763).

\section{Disclosure}

The authors report no potential conflicts of interest in this work.

\section{References}

1. Ferlay J, Soerjomataram I, Dikshit R, et al. Cancer incidence and mortality worldwide: sources, methods and major patterns in GLOBOCAN 2012. Int J Cancer. 2015;136(5):E359-86. doi:10.1002/ijc.29210

2. Bray F, Ferlay J, Soerjomataram I, Siegel RL, Torre LA, Jemal A. Global cancer statistics 2018: GLOBOCAN estimates of incidence and mortality worldwide for 36 cancers in 185 countries. CA Cancer J Clin. 2018;68(6):394-424. doi:10.3322/caac.21492

3. Arbyn M, Weiderpass E, Bruni L, et al. Estimates of incidence and mortality of cervical cancer in 2018: a worldwide analysis. Lancet Glob Health. 2020;8(2):e191-e203. doi:10.1016/S2214-109X(19) 30482-6

4. Francis SA, Nelson J, Liverpool J, Soogun S, Mofammere N, Thorpe RJ. Examining attitudes and knowledge about HPV and cervical cancer risk among female clinic attendees in Johannesburg, South Africa. Vaccine. 2010;28(50):8026-8032. doi:10.1016/j. vaccine.2010.08.090

5. Clifford GM, Smith JS, Plummer M, Munoz N, Franceschi S. Human papillomavirus types in invasive cervical cancer worldwide: a meta-analysis. $B r \quad J$ Cancer. 2003;88(1):63-73. doi:10.1038/sj. bjc. 6600688

6. Bosch FX, de Sanjose S. Chapter 1: human papillomavirus and cervical cancer-burden and assessment of causality. J Natl Cancer Inst Monogr. 2003;1(31):3-13. doi:10.1093/oxfordjournals.jncimonographs.a003479

7. Moody CA, Laimins LA. Human papillomavirus oncoproteins: pathways to transformation. Nat Rev Cancer. 2010;10(8):550-560. doi: $10.1038 / \mathrm{nrc} 2886$

8. Taghizadeh E, Jahangiri S, Rostami D, et al. Roles of E6 and E7 Human Papillomavirus Proteins in Molecular Pathogenesis of Cervical Cancer. Curr Protein Pept Sci. 2019;20(9):926-934. doi:10.2174/1389203720666190618101441

9. Pett M, Coleman N. Integration of high-risk human papillomavirus: a key event in cervical carcinogenesis? J Pathol. 2007;212 (4):356-367. doi:10.1002/path.2192

10. Hu Z, Zhu D, Wang W, et al. Genome-wide profiling of HPV integration in cervical cancer identifies clustered genomic hot spots and a potential microhomology-mediated integration mechanism. Nat Genet. 2015;47(2):158-163. doi:10.1038/ng.3178

11. Pal A, Kundu R. Human Papillomavirus E6 and E7: the Cervical Cancer Hallmarks and Targets for Therapy. Front Microbiol. 2019;10:3116. doi:10.3389/fmicb.2019.03116 
12. Hildesheim A, Herrero R, Wacholder S, et al. Effect of human papillomavirus 16/18 L1 viruslike particle vaccine among young women with preexisting infection - A randomized trial. JAMA-J Am Med Assoc. 2007;298(7):743-753. doi:10.1001/jama.298.7.743

13. Ciavattini A, Clemente N, Carpini GD, et al. Loop electrosurgical excision procedure and risk of miscarriage. Fertil Steril. 2015;103 (4):1043-1048. doi:10.1016/j.fertnstert.2014.12.112

14. Pahle J, Walther W. Vectors and strategies for nonviral cancer gene therapy. Expert Opin Biol Ther. 2016;16(4):443-461. doi:10.1517/ 14712598.2016.1134480

15. Zhang J, Ding M, Xu K, Mao L, Zheng J. shRNA-armed conditionally replicative adenoviruses: a promising approach for cancer therapy. Oncotarget. 2016;7(20):29824-29834. doi:10.18632/ oncotarget. 8035

16. Dominguez AA, Lim WA, Qi LS. Beyond editing: repurposing CRISPR-Cas9 for precision genome regulation and interrogation. Nat Rev Mol Cell Biol. 2016;17(1):5-15. doi:10.1038/nrm.2015.2

17. Almeida AM, Queiroz JA, Sousa F, Sousa A. Cervical cancer and HPV infection: ongoing therapeutic research to counteract the action of E6 and E7 oncoproteins. Drug Discov Today. 2019;24 (10):2044-2057. doi:10.1016/j.drudis.2019.07.011

18. Evers B, Jastrzebski K, Heijmans JP, Grernrum W, Beijersbergen RL, Bernards R. CRISPR knockout screening outperforms shRNA and CRISPRi in identifying essential genes. Nat Biotechnol. 2016;34 (6):631-633. doi:10.1038/nbt.3536

19. Chen M, Mao A, Xu M, Weng Q, Mao J, Ji J. CRISPR-Cas9 for cancer therapy: opportunities and challenges. Cancer Lett. 2019;447:48-55. doi:10.1016/j.canlet.2019.01.017

20. Song X, Liu C, Wang N, et al. Delivery of CRISPR/Cas systems for cancer gene therapy and immunotherapy. Adv Drug Deliv Rev. 2021;168:158-180. doi:10.1016/j.addr.2020.04.010

21. Sharma G, Sharma AR, Bhattacharya M, Lee SS. Chakraborty C. CRISPR-Cas9: a Preclinical and Clinical Perspective for the Treatment of Human Diseases. Mol Ther. 2021;29(2):571-586. doi:10.1016/j.ymthe.2020.09.028

22. Xiao B, Laroui H, Viennois E, et al. Nanoparticles with surface antibody against CD98 and carrying CD98 small interfering RNA reduce colitis in mice. Gastroenterology. 2014;146(5):1289-300 e119. doi:10.1053/j.gastro.2014.01.056

23. Xu CF, Chen GJ, Luo YL, et al. Rational designs of in vivo CRISPR-Cas delivery systems. Adv Drug Deliv Rev 2021;168:3-29. doi:10.1016/j.addr.2019.11.005

24. Weber W, Fussenegger M. Pharmacologic transgene control systems for gene therapy. J Gene Med. 2006;8(5):535-556. doi:10.1002/jgm.903

25. Zhou Z, Liu X, Zhu D, et al. Nonviral cancer gene therapy: delivery cascade and vector nanoproperty integration. Adv Drug Deliv Rev. 2017;115:115-154. doi:10.1016/j.addr.2017.07.021

26. Li J, Roise JJ, He M, Das R, Murthy N. Non-viral strategies for delivering genome editing enzymes. Adv Drug Deliv Rev. 2021;168:99-117. doi:10.1016/j.addr.2020.09.004

27. Ma K, Mi CL, Cao XX, Wang TY. Progress of cationic gene delivery reagents for non-viral vector. Appl Microbiol Biotechnol. 2021;105 (2):525-538. doi:10.1007/s00253-020-11028-6

28. Wang DY, Yang G, van der Mei HC, Ren Y, Busscher HJ, Shi L. Liposomes with Water as a pH-Responsive Functionality for Targeting of Acidic Tumor and Infection Sites. Angew Chem Int Ed Engl. 2021;60(32):17714-17719. doi:10.1002/anie.202106329

29. Radmanesh F, Sadeghi Abandansari H, Ghanian MH, et al. Hydrogelmediated delivery of microRNA-92a inhibitor polyplex nanoparticles induces localized angiogenesis. Angiogenesis. 2021;24(3):657-676. doi:10.1007/s10456-021-09778-6

30. Zhu D, Shen H, Tan S, et al. Nanoparticles Based on Poly (beta-Amino Ester) and HPV16-Targeting CRISPR/shRNA as Potential Drugs for HPV16-Related Cervical Malignancy. Mol Ther. 2018;26(10):2443-2455. doi:10.1016/j.ymthe.2018.07.019
31. Zhang H, Li J, Yuan R, et al. Augment the efficacy of eradicating metastatic lesions and tumor proliferation in breast cancer by honokiol-loaded $\mathrm{pH}$-sensitive targeted lipid nanoparticles. Colloids Surf B Biointerfaces. 2021;207:112008. doi:10.1016/j.colsurfb.2021. 112008

32. Guerrero-Cazares H, Tzeng SY, Young NP, Abutaleb AO, QuinonesHinojosa A, Green JJ. Biodegradable Polymeric Nanoparticles Show High Efficacy and Specificity at DNA Delivery to Human Glioblastoma in Vitro and in Vivo. Acs Nano. 2014;8 (5):5141-5153. doi:10.1021/nn501197v

33. Tzeng SY, Higgins LJ, Pomper MG, Green JJ. Student award winner in the Ph.D. category for the 2013 society for biomaterials annual meeting and exposition, April 10-13, 2013, Boston, Massachusetts: biomaterial-mediated cancer-specific DNA delivery to liver cell cultures using synthetic poly(beta-amino ester)s. J Biomed Mater Res A. 2013;101(7):1837-1845. doi:10.1002/jbm.a.34616

34. Kim J, Kang Y, Tzeng SY, Green JJ. Synthesis and application of poly(ethylene glycol)-co-poly(beta-amino ester) copolymers for small cell lung cancer gene therapy. Acta Biomater. 2016;41:293-301. doi:10.1016/j.actbio.2016.05.040

35. Kaczmarek JC, Patel AK, Rhym LH, et al. Systemic delivery of mRNA and DNA to the lung using polymer-lipid nanoparticles. Biomaterials. 2021;275:120966. doi:10.1016/j.biomaterials.2021.12 0966

36. Guo R, Li K, Tian B, et al. Elaboration on the architecture of $\mathrm{pH}$-sensitive surface charge-adaptive micelles with enhanced penetration and bactericidal activity in biofilms. J Nanobiotechnology. 2021;19(1):232. doi:10.1186/s12951-021-00980-8

37. Bechtold V, Beard P, Raj K. Human papillomavirus type 16 E2 protein has no effect on transcription from episomal viral DNA. J Virol. 2003;77(3):2021-2028. doi:10.1128/Jvi.77.3.2021-2028.2003

38. Kamat CD, Shmueli RB, Connis N, Rudin CM, Green JJ, Hann CL. Poly(beta-amino ester) Nanoparticle Delivery of TP53 Has Activity against Small Cell Lung Cancer In Vitro and In Vivo. Mol Cancer Ther. 2013;12(4):405-415. doi:10.1158/1535-7163.Mct-12-0956

39. Anderson DG, Peng WD, Akinc A, et al. A polymer library approach to suicide gene therapy for cancer. P Natl Acad Sci USA. 2004;101 (45):16028-16033. doi:10.1073/pnas.0407218101

40. Sudenga SL, Shrestha S. Key considerations and current perspectives of epidemiological studies on human papillomavirus persistence, the intermediate phenotype to cervical cancer. Int J Infect Dis. 2013;17 (4):e216-20. doi:10.1016/j.ijid.2012.12.027

41. Elfstrom KM, Arnheim-Dahlstrom L, von Karsa L, Dillner J. Cervical cancer screening in Europe: quality assurance and organisation of programmes. Eur J Cancer. 2015;51(8):950-968. doi:10. 1016/j.ejca.2015.03.008

42. Goldhaber-Fiebert JD, Goldie SJ. Estimating the cost of cervical cancer screening in five developing countries. Cost Eff Resour Alloc. 2006;4:13. doi:10.1186/1478-7547-4-13

43. Campos NG, Sharma M, Clark A, Kim JJ, Resch SC. Resources Required for Cervical Cancer Prevention in Low- and Middle-Income Countries. PLoS One. 2016;11(10):e0164000. doi:10.1371/journal.pone. 0164000

44. Kirkegaard P, Gustafson LW, Petersen LK, Andersen B. 'I Want the Whole Package'. Elderly Patients' Preferences for Follow-Up After Abnormal Cervical Test Results: a Qualitative Study. Patient Prefer Adherence. 2020;14:1185-1193. doi:10.2147/PPA.S259095

45. Gilham C, Crosbie EJ, Peto J. Cervical cancer screening in older women. BMJ. 2021;372:n280. doi:10.1136/bmj.n280

46. Jonson AL, Rogers LM, Ramakrishnan S, Downs LS Jr. Gene silencing with siRNA targeting E6/E7 as a therapeutic intervention in a mouse model of cervical cancer. Gynecol Oncol. 2008;111 (2):356-364. doi:10.1016/j.ygyno.2008.06.033

47. Castanotto D, Rossi JJ. The promises and pitfalls of RNA-interferencebased therapeutics. Nature. 2009;457(7228):426-433. doi:10.1038/ nature 07758 
48. Kim J, Sunshine JC, Green JJ. Differential Polymer Structure Tunes Mechanism of Cellular Uptake and Transfection Routes of Poly (beta-amino ester) Polyplexes in Human Breast Cancer Cells. Bioconjugate Chem. 2014;25(1):43-51. doi:10.1021/bc4002322

49. Mastorakos P, da Silva AL, Chisholm J, et al. Highly compacted biodegradable DNA nanoparticles capable of overcoming the mucus barrier for inhaled lung gene therapy. Proc Natl Acad Sci USA. 2015;112(28):8720-8725. doi:10.1073/pnas.1502281112

50. Min S, Jin Y, Hou CY, et al. Bacterial tRNase-Based Gene Therapy with Poly(beta-Amino Ester) Nanoparticles for Suppressing Melanoma Tumor Growth and Relapse. Adv Healthc Mater. 2018;7 (16):e1800052. doi:10.1002/adhm.201800052

51. Jung HS, Rajasekaran N, Ju W, Shin YK. Human Papillomavirus: current and Future RNAi Therapeutic Strategies for Cervical Cancer. J Clin Med. 2015;4(5):1126-1155. doi:10.3390/jcm4051126

52. Chen Z, Liu F, Chen Y, et al. Targeted Delivery of CRISPR/ Cas9-Mediated Cancer Gene Therapy via Liposome-Templated Hydrogel Nanoparticles. Adv Funct Mater. 2017;27:46. doi:10.1002/ adfm. 201703036

53. Woodrow KA, Cu Y, Booth CJ, Saucier-Sawyer JK, Wood MJ, Saltzman WM. Intravaginal gene silencing using biodegradable polymer nanoparticles densely loaded with small-interfering RNA. Nat Mater. 2009;8(6):526-533. doi:10.1038/nmat2444

54. Jones CH, Chen M, Ravikrishnan A, et al. Mannosylated poly(beta-amino esters) for targeted antigen presenting cell immune modulation. Biomaterials. 2015;37:333-344. doi:10.1016/j.biomaterials.2014.10.037
55. Yang F, Cho SW, Son SM, et al. Genetic engineering of human stem cells for enhanced angiogenesis using biodegradable polymeric nanoparticles. Proc Natl Acad Sci U S A. 2010;107(8):3317-3322. doi:10.1073/pnas.0905432106

56. Palmeira-de-oliveira R, Palmeira-de-oliveira A, Martinez-de-oliveira J. New strategies for local treatment of vaginal infections. Adv Drug Deliv Rev. 2015;92:105-122. doi:10.1016/j.addr.2015.06.008

57. Moon SB, Kim DY, Ko JH, Kim YS. Recent advances in the CRISPR genome editing tool set. Exp Mol Med. 2019;51(11):1-11. doi:10.1038/s12276-019-0339-7

58. Kumar A, Rathi E, Hariharapura RC, Kini SG. Is viral E6 oncoprotein a viable target? A critical analysis in the context of cervical cancer. Med Res Rev. 2020;40(5):2019-2048. doi:10.1002/med.21697

59. Kamal M, Lameiras S, Deloger M, et al. Human papilloma virus (HPV) integration signature in Cervical Cancer: identification of MACROD2 gene as HPV hot spot integration site. $\mathrm{Br} J$ Cancer. 2021;124(4):777-785. doi:10.1038/s41416-020-01153-4

60. Baumann A, Henriques J, Selmani Z, et al. HPV16 Load Is a Potential Biomarker to Predict Risk of High-Grade Cervical Lesions in High-Risk HPV-Infected Women: a Large Longitudinal French Hospital-Based Cohort Study. Cancers. 2021;13:16. doi:10.3390/cancers 13164149
International Journal of Nanomedicine

\section{Publish your work in this journal}

The International Journal of Nanomedicine is an international, peerreviewed journal focusing on the application of nanotechnology in diagnostics, therapeutics, and drug delivery systems throughout the biomedical field. This journal is indexed on PubMed Central, MedLine, CAS, SciSearch ${ }^{\mathbb{}}$, Current Contents ${ }^{\mathbb{R}} /$ Clinical Medicine, $^{2}$

\section{Dovepress}

Journal Citation Reports/Science Edition, EMBase, Scopus and the Elsevier Bibliographic databases. The manuscript management system is completely online and includes a very quick and fair peer-review system, which is all easy to use. Visit http://www.dovepress.com/ testimonials.php to read real quotes from published authors. 